\title{
POLA TATA RUANG PERUMAHAN DAN PERKEMBANGANNYA DITINJAU DARI KEARIFAN LOKAL DESA CIKOANG
}

\author{
Andi Teddy M; Mimi Arifin; Ninik Dwi Resky, Aris Sakkar Dollah \\ Dosen Prodi Arsitektur, Fakultas Teknik, Universitas Muhammadiyah, Makassar. \\ Dosen Prodi Perencanaan Wilayah Kota, Fakultas Teknik, Universitas Hasanuddin. \\ Mahasiswa Prodi Perencanaan Wilayah Kota, FakultasTeknik, Universitas Hasanuddin \\ Dosen Prodi Arsitektur, Fakultas Teknik, Universitas Muhammadiyah, Makassar. \\ E-mail: mappateddy@yahoo.com, risdollah@gmail.com
}

\begin{abstract}
ABSTRAK
Desa adat merupakan sebuah permukiman tradisional yang memiliki tradisi yang masih dipertahankan sampai saat ini seperti Maudu Lompoa, yang dilakukan setahun sekali dan dijadikan sebagai wisata budaya di Sulawesi Selatan. Hal tersebut mendorong pertumbuhan permukiman di sekitar ruang kegiatan budaya yang dapat menurunkan daya dukung kawasan perumahan. Oleh sebab itu, perlu mengidentifikasi karakteristik fisik pola tata ruang perumahan dan perkembangannya ditinjau dari kearifan lokal. Adapun teknik pengumpulan data dengan cara observasi, wawancara, dokumentasi, studi pustaka, penyebaran kuesioner dan pendataan instansional. Metode yang digunakan adalah analisis deskriptif kualitatif, komparatif, spasial dan grid index. Hasil penelitian menunjukkan perkembangan perumahan mengikuti ruang yang tersedia di sekitar ruang kegiatan budaya. Pemakaian ruang kegiatan budaya yang tetap. Pola perumahan terikat dengan ruang kegiatan budaya.

Kata kunci: Perkembangan, perumahan, ruang, budaya
\end{abstract}

\section{PENDAHULUAN}

Desa adat merupakan sebuah permukiman tradisional yang masih ada sampai saat ini. Desa Cikoang memiliki ciri khas tersendiri untuk permukiman tradisionalnya dan beberapa tradisi yang masih dipertahankan sampai saat ini seperti maudu lompoa.

Cikoang adalah salah satu daerah yang juga masih melaksanakan peringatan maulid dengan nilai-nilai budaya yang masih cukup kental. Perayaan maulidnya dikenal dengan nama maudu lompoa. Sama halnya seperti perayaan-perayaan maulid yang lain, maudu lompoa juga mendapat banyak kecaman dari berbagai pihak, khususnya kalangan ulama. Namun hingga saat ini maudu lompoa tetap bisa berlangsung setiap tahunnya dengan tetap mempertahankan budaya yang diwariskan nenek moyang mereka.

Hal menarik lain dari tradisi maulid di Cikoang ini adalah tradisi mudiknya yang menyerupai tradisi mudik lebaran. Warga Cikoang sebagai kawasan peruntukan wisata budaya dan religi berdasarkan peraturan RTRW Kabupaten Takalar tahun 2012-2032. Namun, Hal tersebut mendorong pertumbuhan permukiman di sekitar ruang kegiatan budaya yang dapat menurunkan daya dukung kawasan perumahan.

\section{TUJUAN}

Tujuan penelitian adalah untuk mengidentifikasi karakteristik fisik pola tata ruang perumahan dan perkembangannya ditinjau dari kearifan lokal, tata tapak perumahan ditinjau terhadap strata sosial dan ekonomi masyarakat dan menjelaskan prinsip-prinsip penataan tapak perumahan masyarakat adat di Desa Cikoang, Kabupaten Takalar.

\section{METODE PENELITIAN}

Jumlah populasi dalam penelitian ini sebanyak 3.305 jiwa berdasarkan jumlah penduduk pada Desa Cikoang. Sementara untuk pengambilan sampel dilakukan dengan metode nonprobability sampling dengan menggunakan purporsive sampling untuk mengetahui jumlah sampel menggunakan rumus Slovin, yaitu 100 sampel.

Teknik pengumpulan data dengan observasi, wawancara, dokumentasi, studi pustaka, penyebaran kuesioner dan pendataan instansional yang berhubungan dengan materi yang akan disusun. Teknik analisis yang digunakan yaitu deskriptif menggunakan analisis deskriptif kualitatif, spasial, komparatif dan grid index. 


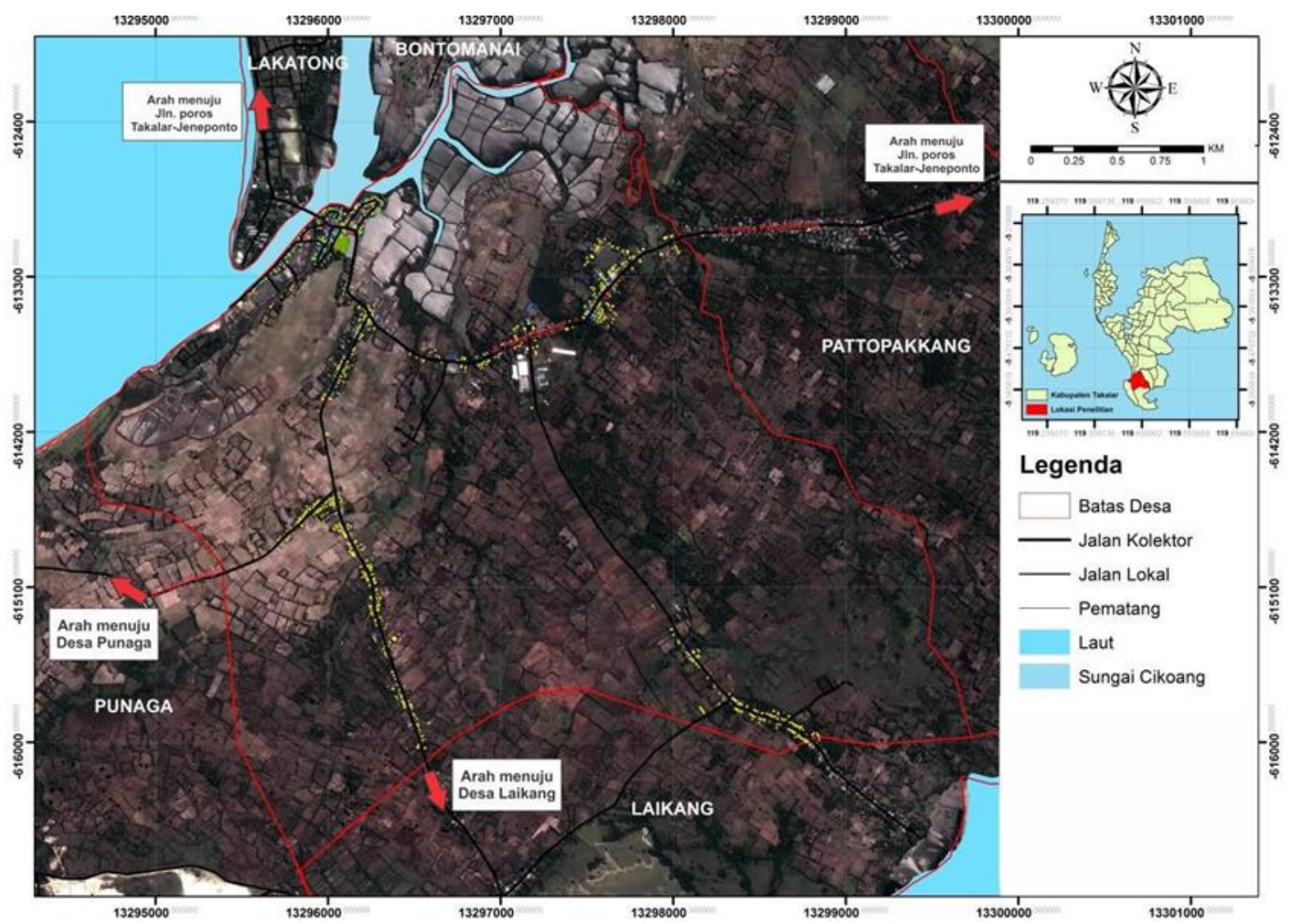

(Sumber: Analisis Penelitian, 2018)

Gambar 1. Peta Lokasi Penelitian

\section{ANALISIS DAN PEMBAHASAN}

Analisis Karakteristik Fisik Pola Tata Ruang Perumahan Masyarakat Adat Sejarah awal terbentuknya perumahan

Awal mula terbentuknya Desa Cikoang bermula karena adanya perjanjian jual beli tanah yang dilakukan oleh seseorang dari Binamu bernama Karaeng Cikondong kepada Raja Gowa. Setelah itu Karaeng Cikondong bersama pengikutnya membangun suatu permukiman baru, sehingga terbentuk perumahan masyarakat adat yang berada di sekitar sungai Cikoang yang berorientasi menghadap ke sungai. Perkembangan permukiman di Desa Cikoang di tandai dengan kedatangan Sayyid Jalaluddin Al-Aidid yang menyebarkan Islam.

\section{Perkembangan perumahan masyarakat adat}

Perkembangan perumahan di Desa Cikoang, dapat diketahui dengan melihat peta time series dalam kurun waktu 11 tahun terakhir yaitu perumahan yang terbangun pada tahun 2006-2009, 2010-2013, dan
2014-2017. Dari analisis tersebut dapat dilihat persentase jumlah grid dan rumah dalam kurun waktu 11 tahun di lokasi penelitian.

Tabel 1. Jumlah Grid dan Rumah dalam Kurun Waktu 11 Tahun

\begin{tabular}{ccccc}
\hline Tahun & $\begin{array}{c}\text { Jumlah Persentase } \\
\text { Grid }\end{array}$ & $\begin{array}{c}\text { Jumlah } \\
\text { Rumah }\end{array}$ & $\begin{array}{c}\text { Persentase } \\
(\%)\end{array}$ \\
\hline $2006-2009$ & 60 & $25,21 \%$ & 265 & $31,66 \%$ \\
\hline $2010-2013$ & 114 & $47,9 \%$ & 336 & $40,14 \%$ \\
\hline $2014-2017$ & 64 & $26,89 \%$ & 236 & $28,2 \%$ \\
\hline Jumlah & 238 & $100 \%$ & 837 & $100 \%$ \\
\hline
\end{tabular}

(Sumber: Hasil Analisis, 2018)

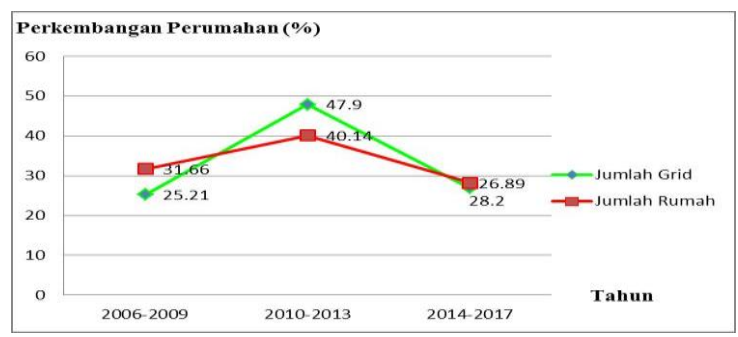

(Sumber: Analisis Penelitian, 2018) 
Gambar 2. Grafik Perkembangan Perumahan, Tahun 2006-2017

Berdasarkan gambar 2 jumlah grid yang terbangun sebelum tahun 2005 sebanyak 142 grid di lokasi penelitian. Jumlah grid yang terbangun pada tahun 2006-2009 sebanyak 60 grid yaitu 25,21\% dan 265 unit rumah yaitu sebesar $31,66 \%$ dari total jumlah grid dan rumah dalam kurun waktu 2006-2017, dimana jumlah grid yang terbangun pada tahun 2009 menjadi 202 grid di lokasi penelitian.

Jumlah grid yang terbangun pada tahun 2010-2013 sebanyak 114 grid yaitu 47,9\% dan 336 unit rumah yaitu sebesar 40,14\% dari total jumlah grid dan rumah dalam kurun waktu 2006-2017, dimana jumlah grid yang terbangun pada tahun 2013 menjadi 316 grid di lokasi penelitian.

Jumlah grid yang terbangun pada tahun 2014-2017 sebanyak 64 grid yaitu $26,89 \%$ dan 236 unit rumah yaitu sebesar $28,2 \%$ dari total jumlah grid dan rumah dalam kurun waktu 2006-2017, dimana jumlah grid yang terbangun pada tahun 2017 menjadi 380 grid di lokasi penelitian.

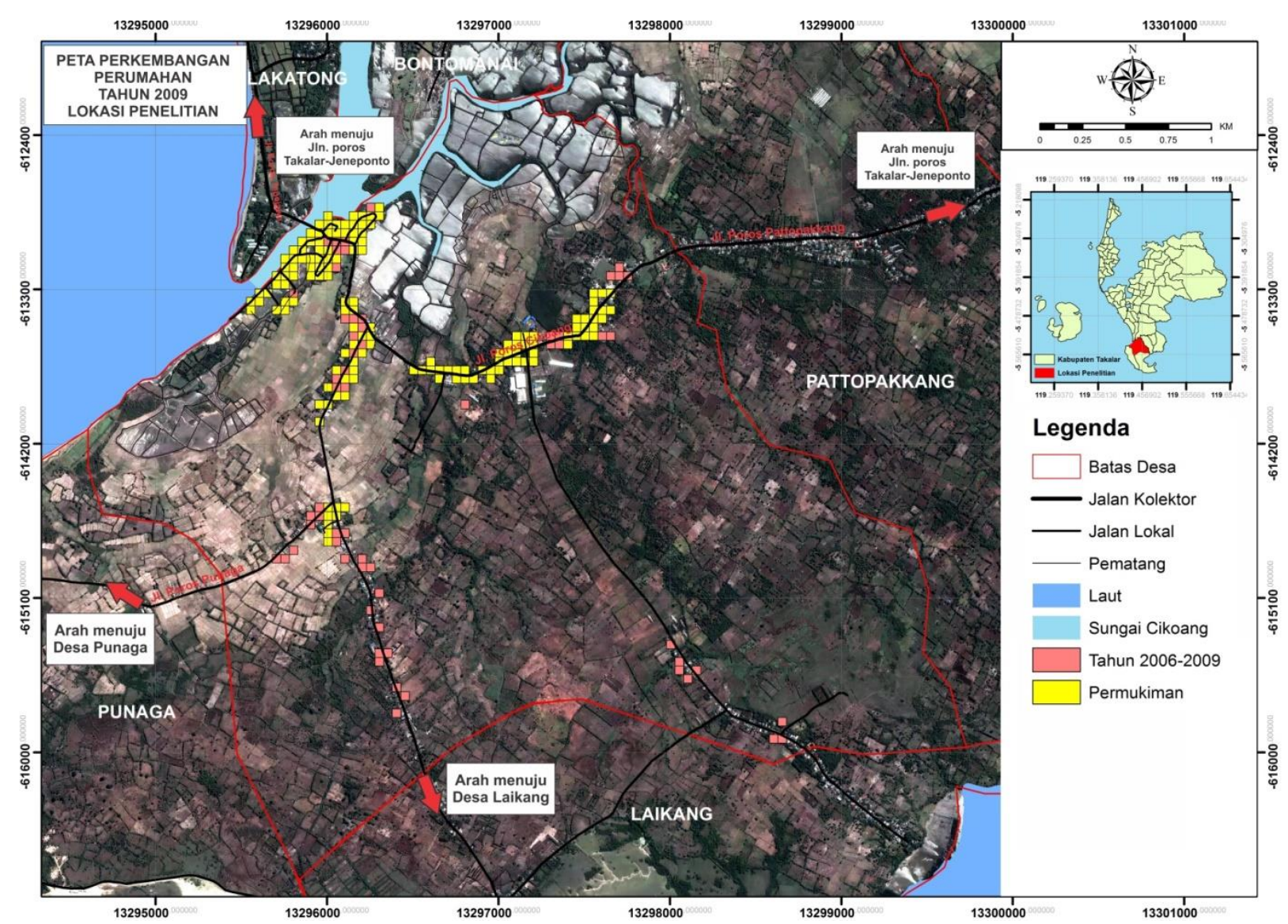

(Sumber: Analisis Penelitian, 2018)

Gambar 3. Peta Perkembangan Perumahan, Tahun 2009 


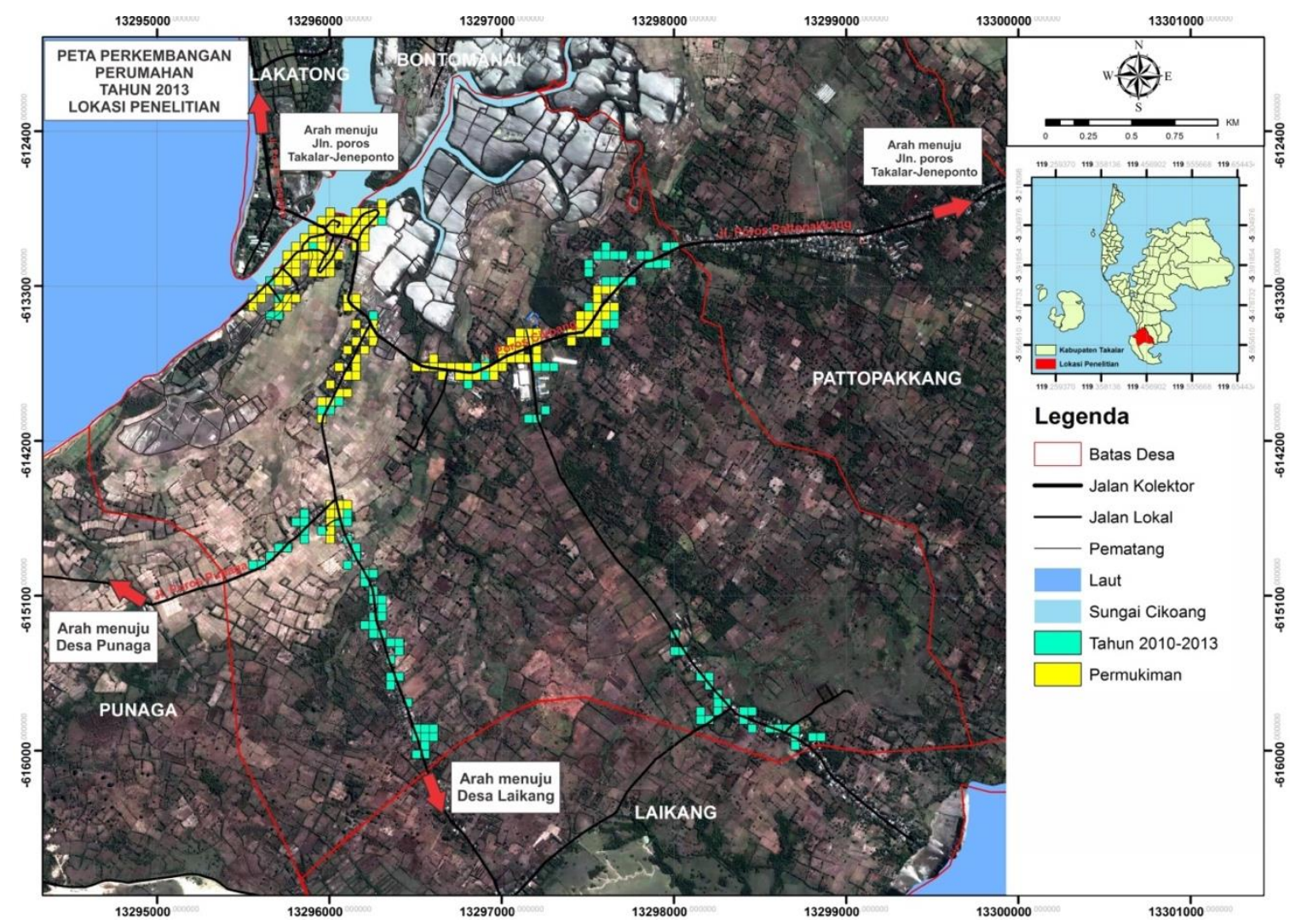

(Sumber: Analisis Penelitian, 2018)

Gambar 4. Peta Perkembangan Perumahan, Tahun 2013

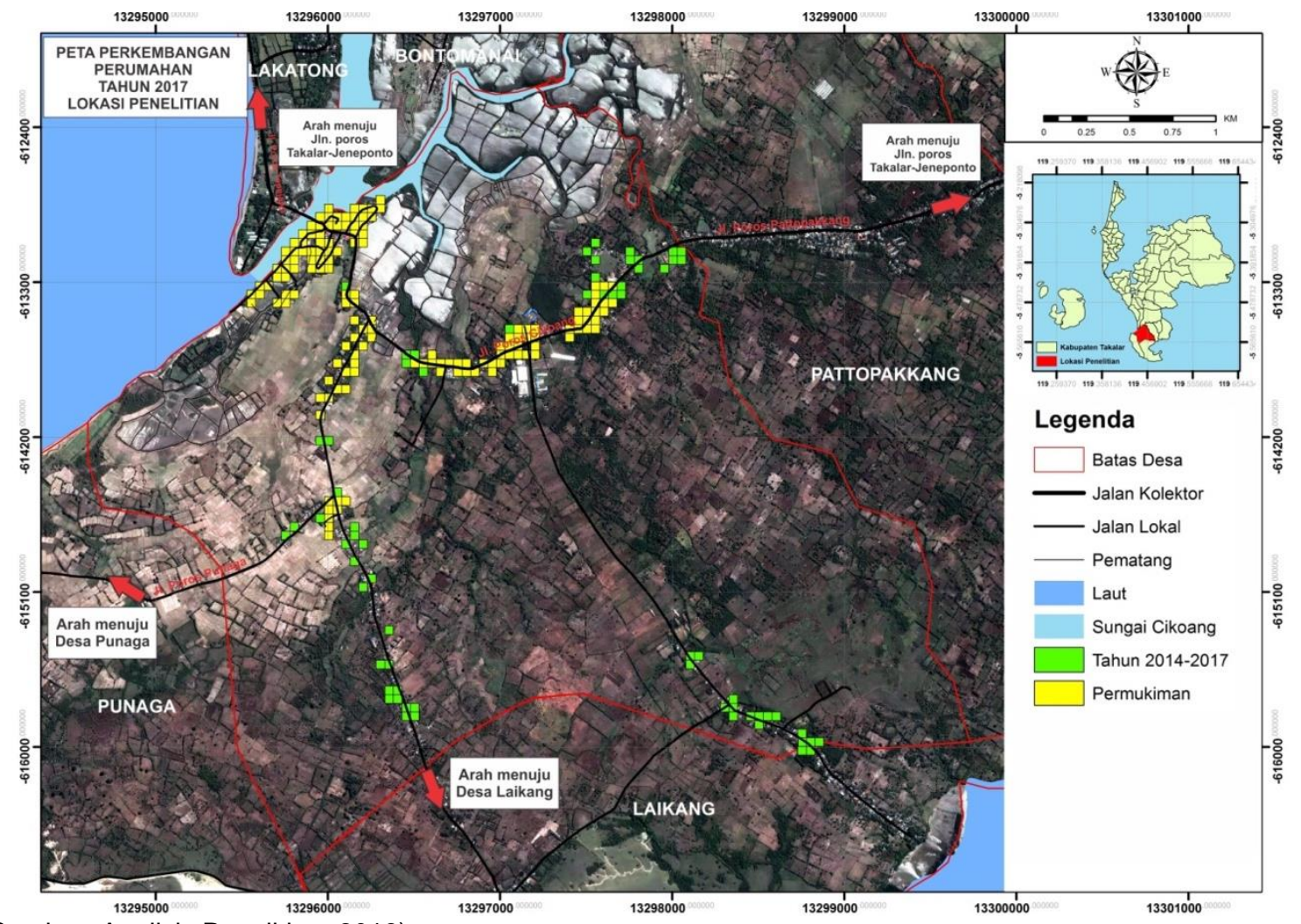

(Sumber: Analisis Penelitian, 2018)

Gambar 5. Peta Perkembangan Perumahan, Tahun 2017 


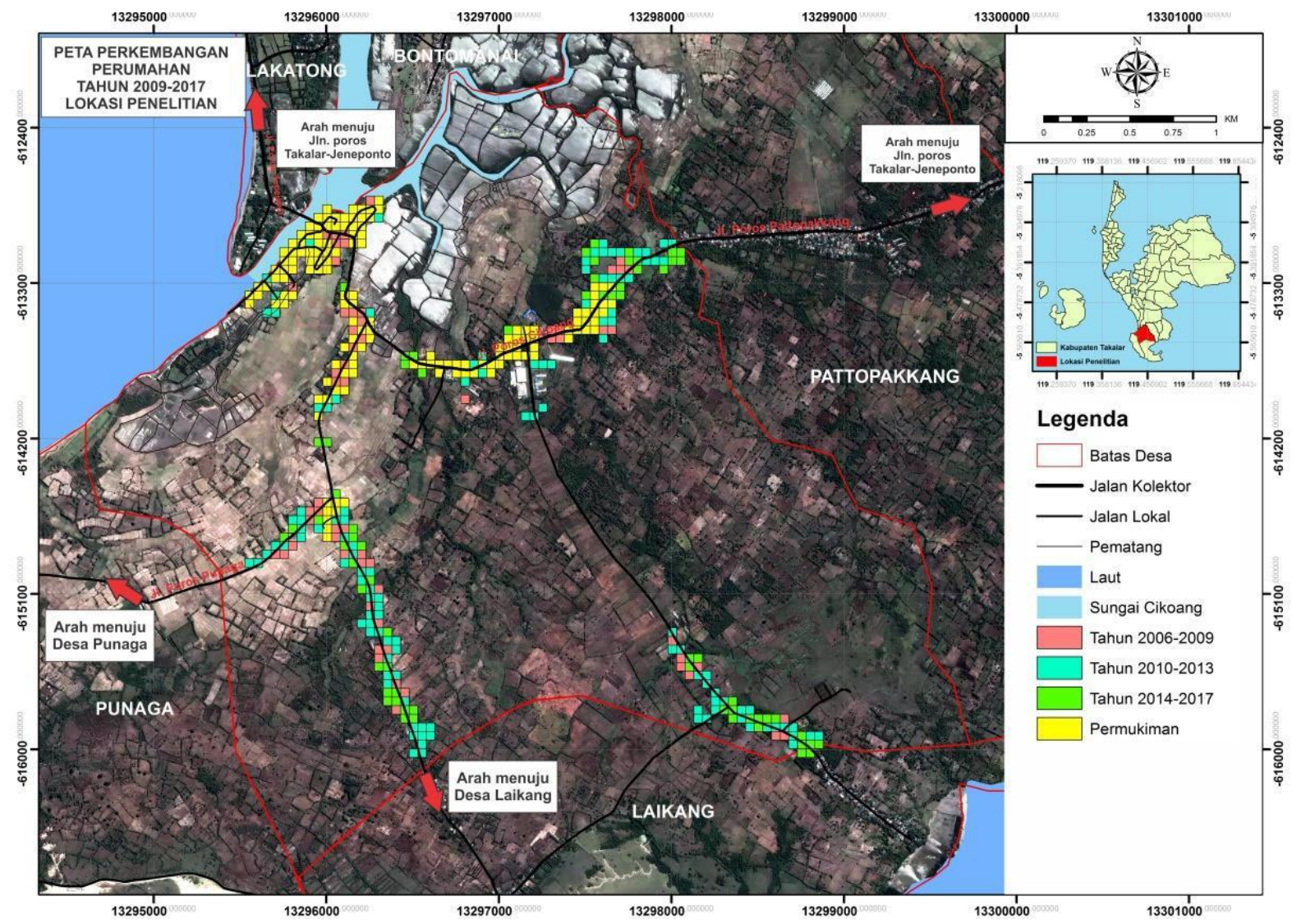

(Sumber: Analisis Penelitian, 2018)

Gambar 6. Peta Perkembangan Perumahan, Tahun 2006-2017

\section{Ruang Budaya}

Ruang budaya di Desa Cikoang terdiri dari ruang untuk perayaan maudu lompoa, perayaan maulid Nabi Muhammad SAW dan mandi syafar.

\section{Perayaan maudu lompoa}

Maudu' berarti Maulid Besar atau lebih dikenal sebagai puncak peringatan maulid yang telah dimulai sejak tahun 1621. Kegiatan ini ditujukan untuk menanamkan kecintaan kepada Nabi Muhammad SAW dan keluarganya. Maudu Lompoa merupakan pesta keagamaan masyarakat Cikoang yang sarat dengan nilai-nilai budaya yang terus dilestarikan turuntemurun.

Menurut Sasongko (2005:89) konteks budaya terkait dengan ruang permukiman menyatakan untuk menjelaskan makna dari organisasi ruang dalam konteks tempat (place) dan ruang (space) harus dikaitkan dengan budaya.
Perayaan Maudu Lompoa atau maulid Nabi Muhammad SAW merupakan ritual yang bersifat permanen, karena dilaksanakan rutin sekali setahun di sepanjang sungai Cikoang, baruga dan rumah adat Karaeng Laikang.

Menurut Arifin, Mimi (2013) baruga digunakan hanya pada saat-saat tertentu secara periodik, karena lebih sering tidak termanfaatkan, sehingga cenderung berfungsi sebagai simbol teritori. 


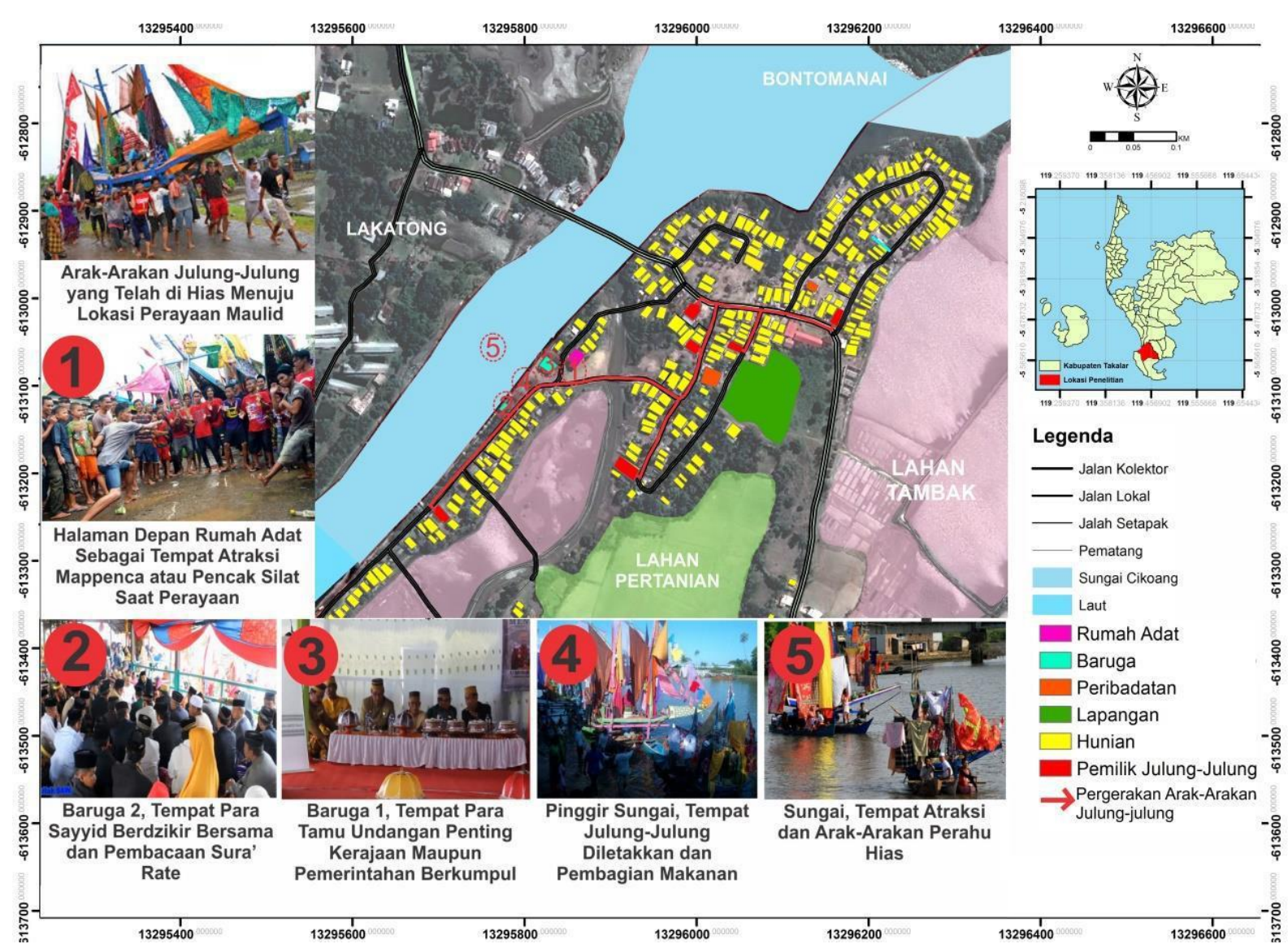

(Sumber: Analisis Penelitian, 2018)

Gambar 7. Peta Ruang Kegiatan Budaya dan Pergerakan Pada Maudu Lompoa

\section{Maulid Nabi Muhammad SAW (Maulid Kecil)}

Berdasarkan hasil wawancara dengan bapak Muhammad Jufri, S.pd (Kepala Desa Cikoang), kegiatan maulid Nabi Muhammad SAW di Desa Cikoang dari dulu sekarang dilaksanakan di sungai, rumah adat dan baruga. Hal tersebut menunjukkan pemakaian ruang yang tetap pada perayaan maulid sebagai tempat ritual. Perayaan maulid dilaksanakan secara bergilir yakni sekitar \pm 16 hari (12-28 Rabiul Awal) dengan orang yang merayakan berbeda-beda setiap harinya di masjid-mesjid desa Cikoang dengan pembacaan kitab barazanji (kitab sejarah Nabi Muhammad).

\section{Mandi syafar}

Upacara ini dilaksanakan pada tanggal 10 bulan shafar menurut perhitungan tahun hijriah. Masyarakat Desa meyakini mandi shafar ini menghindarkan mereka dari sakit, bahaya, musibah maupun santet.

Mandi Safar diperuntukkan untuk para lelaki, yang melaksanakan maudu lompoa, selain itu bertujuan mensucikan diri dari hadas. Mandi safar di pimpin oleh anrongguru dan dimulai dengan membaca doa dan dilaksanakan di muara sungai Cikoang.

Hal ini menunjukkan bahwa sungai tetap digunakan sebagai tempat ritual mandi syafar. Selain itu, mandi syafar juga dilaksanakan rutin sekali setahun di sepanjang Sungai Cikoang sebelum perayaan maudu lompoa. 


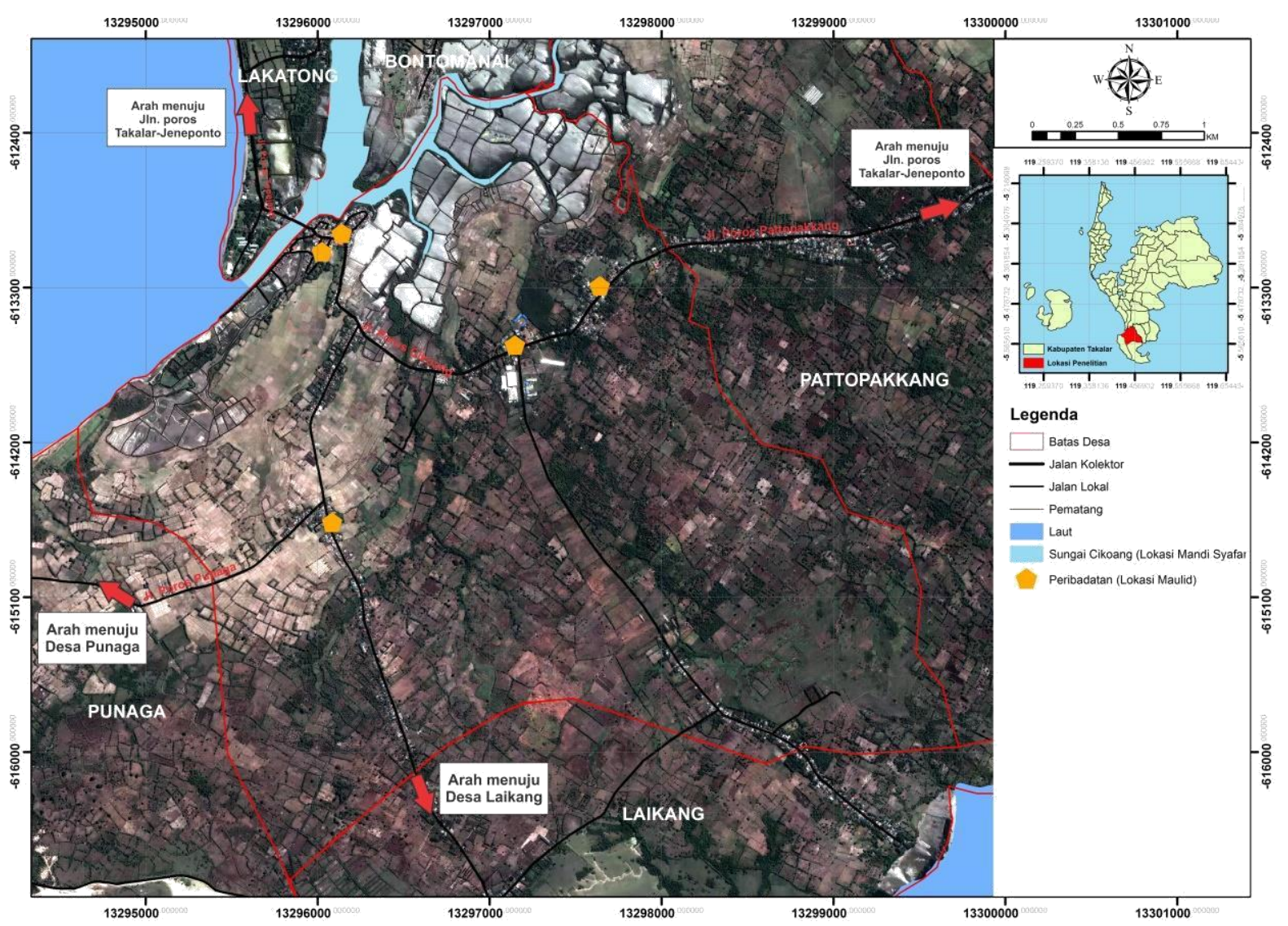

(Sumber: Analisis Penelitian, 2018)

Gambar 8. Peta Lokasi Maulid Kecil dan Mandi Syafar

Adapun kearifan lokal di Desa Cikoang sistem adat sebagai kearifan tradisional dan sistem adat dalam pemanfaatan ruang.

\section{Sistem adat sebagai kearifan lokal}

Sistem adat sebagai kearifan tradisional diterapkan pada (1) sistem pemerintahan, (2) sistem perkawinan, (3) budaya siri' na pacce, (4) ritual persiapan dan pelaksanaan serta benda-benda yang digunakan dalam kegiatan budaya maudu lompoa.

Sistem pemerintahan yang berada di Desa Cikoang memiliki dua sistem, yaitu sistem pemerintahan desa dinas dan sistem pemerintahan desa adat. Sistem pemerintahan dinas dipimpin oleh kepala desa sedangkan sistem pemerintahan adat di pimpin oleh pemangku adat Karaeng Laikang dan Ketua lembaga adat.

Sistem perkawinan dalam pernikahan anak perempuan Sayyid ada aturan tidak tertulis yang harus ditaati, yaitu bagi perempuan Sayyid tidak bisa menikah diluar komunitasnya, apabila perempuan Sayyid menikah diluar komunitasnya maka dia memutuskan garis keturunan Sayyid.

Aturan ini menjadi budaya turuntemurun keturunan Sayyid dalam menentukan jodoh anak peremuan mereka, sedangkan laki-laki Sayyid boleh saja menikah dengan yang bukan Sayyid. Untuk menjaga keutuhan identitas mereka.

Siri' na pacce merupakan budaya asli masyarakat Sayyid Cikoang sebagai masyarakat suku Makassar. Siri' dimaknai sebagai rasa malu yang dijadikan alas an untuk bertindak mempertahankan harga diri. Pacce dimaknai sebagai rasa peduli terhadap sesama manusia. Budaya siri' na pacce perlu untuk dilestarikan dan di perkenalkan kegenerasi muda yang belum memahami budaya lokal. Nilai-nilai yang terkandung dalam implementasi budaya siri' na pacce masyarakat Sayyid Cikoang yaitu (1) nilai kemanusiaan, (2) nilai 
filosofi, (3) nilai susila, (4) nilai religi, (5) nilai kejujuran, (6) nilai solidaritas, dan (7) nilai keberanian. Generasi muda masyarakat Sayyid Cikoang perlu memperhatikan budaya siri' na pacce agar budaya ini tetap lestari dan selaras dengan perkembangan zaman agar tidak tergerus oleh globalisasi.

Adapun ritual yang harus dilakukan dalam rangka persiapan Maudu Lompoa meliputi A'jene-jene sappara (mandi di bulan safar); Anyongko jangang (mengurung ayam); Angngalloi ase (penjemuran padi); A'dengka ase (menumbuk padi); A'tanak minyak (membuat minyak dari kelapa); Anyongkolok kanre (menanak nasi)
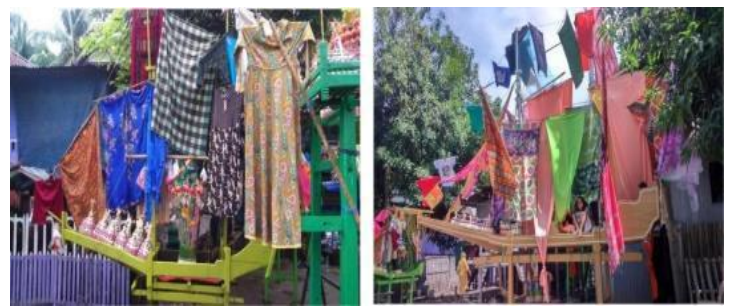

(Sumber: Analisis Penelitian, 2018)

Gambar 9. Persiapan Sebelum Maudu Lompoa

Julung-julung merupakan simbol datangnya ajaran kebenaran dari Nabi Muhammad yang di bawa oleh Sayyid Djalaluddin. Bagi keluarga yang mampu secara finansial di wajibkan membuat satu perahu, sedangkan keluarga yang kurang mampu biasanya berkelompok dengan

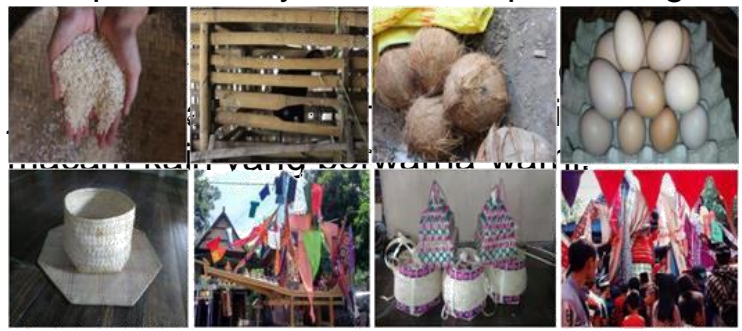

(Sumber: Analisis Penulis, tahun)

(Sumber: Analisis Penelitian, 2018)

Gambar 10. Julung-Julung
Kandawari adalah tempat untuk menyimpan bakul maudu dan atribut maudu lainnya. Kandawari ini berbentuk segi empat dan memiliki kaki yang diperuntukkan bagi 1 keluarga membawa 1 kandawari. Benda ini diibaratkan sebagai kendaraan yang digunakan Nabi pada saat Beliau menemui Allah untuk menerima perintah shalat untuk pertama kalinya. Kendaraan tersebut dinamakan raparaping.

Wujud dari kendaraan yang digunakan Nabi ini untuk melakukan Isra $\square$ Mi $\square$ raj adalah memiliki empat kaki yang kadang kadang menyentuh tanah kadang tidak. Seperti itulah perumpamaan dari kandawari, memiliki empat kaki, jika diangkat (dibembeng) kakinya tidak menyentuh tanah dan jika diletakkan maka akan menyentuh tanah. Pada kandawari dihiasi dengan layar dari berbagai macam kain yang berwarnawarni.

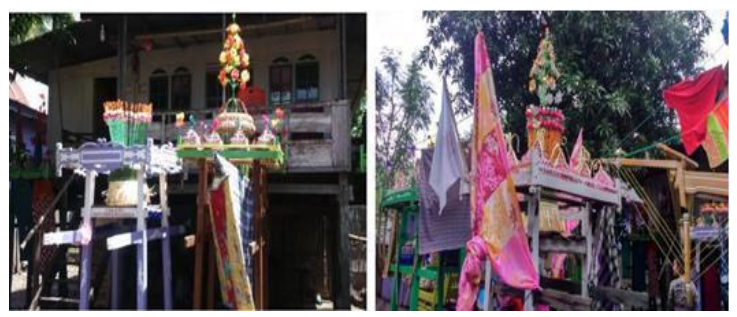

(Sumber: Analisis Penelitian, 2018)

Gambar 11. Julung-Julung

Adapun proses maudu lompoa yaitu: (1) Angngantara' kanre, (2) Maudu Pannarimang' kanre, (3) Maudu A'ratek Azzikkirik, (4) A'toana, (5) A'bage kanre Maudu.

Ritual maudu lompoa tersirat pesanpesan khusus yang ingin disampaikan. Dari keseluruhan ritual, terdapat pesan utama yang ingin diungkapkan dalam pelaksanaan ritual, yaitu pengharapan kepada atas segala keselamatan, kemudahan rejeki, dan yang paling penting dalam ritual ini merupakan bentuk rasa cinta masyarakat kepada Nabinya yakni Nabi Muhammad SAW.

Atraksi Pada Perayaan Maudu Lompoa terdiri dari Appamancak, baku sirang dan lomba lepa-lepa. 


\section{Sistem adat dalam pemanfaatan ruang}

Sistem adat dalam pemanfaatan ruang diterapkan pada pola perumahan dan ruang budaya.

Pola perumahan di Desa Cikoang tidak memiliki aturan tertentu dikarenakan pengaturan rumah diserahkan sepenuhnya kepada pemilik rumah setelah meminta izin kepada pemuka agama untuk dibacakan doa.

Ruang budaya yang terbentuk karena adanya ritual atau kebiasaan-kebiasaan masyarakat dalam menggunakan ruang sebagai tempat perayaan atau kegiatan seperti maudu lompoa, mandi syafar, dan maulid kecil.

\section{DAFTAR PUSTAKA}

Arifin, Mimi. 2017. Ruang Hunian Dalam Perspektif Gender Komunitas Ammatoa Kajang. Makassar, Departemen Perencanaan Wilayah dan Kota Universitas Hasanuddin.

http://rubrik-riza.blogspot.co.id/2017/07/tradisi-maudu-lompoa-di-cikoang.html,

(Diakses tanggal 19 Mei 2018 pukul 14.23).

Rencana Tata Ruang Wilayah (RTRW) Kabupaten Takalar Tahun 2012-2032

Sasongko, Ibnu. 2005. Pembentukan Struktur Ruang Permukiman Berbasis Budaya (Studi Kasus: Desa Puyung-Lombok Tengah). Malang, Planologi, Institut Teknologi Nasional Malang. 